\title{
The Correlation Between Iraqi EFL University Students' Working Memory Capacity and their Language Proficiency
}

\author{
M.A. Candidate Shaymaa Abdul Hussein Al-Mutalebi, Asst. Prof. Dhea Mizhir Krebt. Ph.D. \\ University of Baghdad, College of Education Ibn Rushd
}

DOI: $10.37648 / \mathrm{ijrssh.v10i04.003}$

Received:18 ${ }^{\text {th }}$ July, 2020; Accepted:16th September, 2020; Published:21 st September,2020

\begin{abstract}
An impressive amount of researches have proposed that human beings possess a mental system that is working memory. Working memory is a cognitive part of individual ability with multiple characteristics that allows for information retention and manipulation. The contemporary interest of specialists is that such system has a significant function in learning different linguistic aspects. Students' levels to acquire a foreign language are different, and this could due to the psychological ability that is connected with working memory. Thus, the study investigates the proficiency level of EFL university students and the extent to which it relates to their working memory to outline the efficiency of such capacity in language learning process. For the aim of the study to be achieved, the researcher designs a working memory assessment according to Baddeley's theory and language proficiency test. The major finding confirms that there is a positive correlation between EFL university students' working memory capacity and their language proficiency.

Keywords: Working memory capacity, language proficiency, correlation
\end{abstract}

\section{AIM}

The study aims at finding out the correlation between Iraqi EFL university students' working memory capacity and their language proficiency.

\section{THEORETICAL BACKGROUND}

It becomes obvious that one of the major theoretical issues that have dominated recently is the role of working memory capacity in FL/L2 learning. It is likely to interpret speech production as a process in which both automatic and controlled operations work out in tandem to put up collateral for the execution of speech (Levelt, 1989: 68). Thence, the debates of working memory assessment measures are fundamental in the fields of applied linguistics and FL (Wen, 2012: 43).

\section{The Concept of Working Memory}

Working memory capacity is a prime system that is responsible for temporary storing and exploitation of inputs when there is a demand for recalling data to work on some cognitive tasks which prerequisite for relating previous and novel information, automatically without any intended purposes but achieving the knowledgeable actions.

It is a system that organizes and directs behavior. It tends to be documented in a more classic terms, as "...a set of limiting factors for performance in cognitive tasks" (Oberauer et al., 2003: 168). At its most basic, WM is the brain's ability to restrain attention in the face of interference for the target of processing and manipulating task-relevant information (Wynn \& Coolidge, 2011: 56). 
The span of WMC represents the number of units, items or chunks such as digits, words or figures which can be accurately retrieved by students. Miller (1956: 63) pinpoints the span as the magical number 7 (plus or minus 2) which symbolizes students ability for informational maintenance while Cowan (2001: 35) limits it (4+1) chunks that refers to the amount of attentional resources.

\section{The Concept of Language Proficiency}

Generally, language proficiency is defined as the one's capability to operate a language both for basic communication with others and academic purposes (Basta, 2011: 84). Language proficiency also refers to what level a student can apply speaking, writing, reading and listening skills in addition to how much he/she can absorb the language in context (Richards \& Schmidt, 2002: 18). The three basic criteria for the use of language are "function, context/content, and accuracy" as function symbolizes the student's capability to accomplish an assignment linguistically, such as questioning or explaining something; context/content indicates the functions setting; and accuracy represents the level of precision in sending the message. The ability of the student's language use could be assessed by using these factors and each one of them spreads in range as the level of proficiency enhances (Bragger, 1985: 80).

The researchers' viewpoint is that language proficiency stands for the logical outcomes of linguistic accumulation that a student experienced a either through school or self-learning which are apparently affected by several features with a priority role to decide its level such as student's motivation, attitude and the span of WMC.

\section{The Role of Working Memory in Aspects of FL/L2 Proficiency}

The variations in FL/L2 performance among students is central issue in language learning process as some linguists have a great deal of interest to identify what and how student factors affect processes in SLA domain. (Kormos \& Sáfár, 2008: 267). Ellis (2001: 52) emphasizes that the performance of complex cognitive tasks such as FL/L2 comprehension and production, requiring a system or mechanism supporting the temporary maintenance of information.

Miyake and Friedman (1998: 355) assert that although WM occupies crucial part in each format of higher-level cognition, its function is highlighted explicitly in language processing since that language comprehension and production needs the processing of symbols succession over time in an organized layout. Such linearity intrinsically entails a capacity of temporal storing plus the capacity to merge data from the flow of sequential speech. Accordingly WM regularizes these simultaneous processing and storage necessities perfectly for the current conceptualization (King \& Just, 1991: 588).

The concept of WM appears to be an ideal construct for SLA targets. Service (1992: 39) is one of the first who sought after the connection between non-word repetition and learning new words in FL/L2 as he has discovered that the non-word spans were a tremendous and autonomous predictor of FL/L2 proficiency.

An imperative relation between WMC and FL/L2 proficiency is also assessed through applying reading span test that has been noted by Hummel (2002: 107). A great predictive of reading success is the scores on operating WM tasks for normally developing students; as a result WMC is also noticed to predict reading achievement (Swanson \& Beebe-Frankenberger, 2004: 482). One justification for the critical function of WM in reading, is that the use of WMC for the purpose of having all the relevant speech sounds in mind, merge them with the parallel letters, then coordinate them to read the words.

Proficiency level might overlap with the quality of the sub-procedures immersed in FL/L2 learning, principally the ones that lies beneath sentence construction and lexical retrieval, as in determining the search of vocabulary set sufficiently in order to restrict the amount of lexical choices; deciding on the verbal item that suits the intentional message and; overseeing the selection product (Baddeley \& Hitch, 1974: 63). When FL/L2 students encounter a large difficulty to conduct such sub-processes then they will basically be in need to make use of a larger amount of attentional resources for performing every single step of retrieving the accurate words, that in turns could overload WMC. Furthermore, in producing the sentences verbally students should undertake some processes, among which are the requirement to keep up several memory representations particularly, the lexical chunks that are just recovered and still active in the focus of attention by preventing distraction stimuli when accumulating them into a specified articulation sequence to give them a phonetic form (White et al., 2004: 110).

Studies also begin to examine the role of WMC and spoken production to investigate spoken output in classroom-based research. Mackey et al. (2002: 180) are among the first who observe WMC functions in communication during language 
learning projects. Communication is perceived as an indispensable for FL/L2 acquirement as much as processing, because it guides to such kind of interaction breakdown that enables students to notice the gap as they stuck between what intend to say and their facility of what they express using the right expressions and structures.

It is believed that such noticing during output and negotiation is held to arouse language acquirement through selfcorrection and revised output. Since WMC is allied to noticing, subsequently students with better WMC must have extraordinary learning gains. It has been asserted that higher WMC students took more time to reflect on their output and likened it with prevailing information; yet students who had lower WMC did not (ibid: 205).

One of the applications that account for the processing that students appear to exert in their speech is the inhibitory control model (King \& Just, 1991: 583). In accordance with this model, language performance needs inhibition of the non-target language candidates and managing attentioanl controlled methods (Green, 1998: 75).

In SLA domain, students ought to process in mutual way the form and meaning of input (Fodor, 1998: 136) Thus, those who have more WMC, apparently process more attentional sources and potentially achieve high-level of learning, because they own sufficient memory to process form together with meaning (VanPatten, 2004: 28).

\section{METHODOLOGY}

The present study is intended to identify two variables (working memory capacity and language proficiency) to reveal the sort of the relationship and whether a change in one creates some change in the other or not. College of Education (University of Baghdad) is picked to elicit the sample of the study. The total number of third year is 120 students in University of Baghdad (of both genders). The sample consists of 100 students who have randomly been selected

To achieve the aims of the study, two instruments have been designed namely; working memory assessment and language proficiency test.

\section{Designing Working Memory Assessment}

It has been adopted the definition of working memory capacity linked to Baddeley's Multicomponent Model 2000 to design working memory assessment measures. According to the multi-component model, working memory is a limited capacity part of the human memory system that is capable of briefly storing and manipulating information involved in the service of cognition (Baddeley \& Hitch, 2010: 15).

The final form of the assessment covers all components of working memory and includes 6 tasks. Each task consists of (40) unrelated items or chunks which classified into (10) cards that represent (5) levels. Each level is measured through two successive attempts. The levels are different in term of the number of items. The degree of the tasks is computed on the basis of 0.5 in simple tests and 1 in complex tests for each correct item in the attempt.

To compute the reliability coefficient of instrument, thus, a sample of 30 students is randomly selected from third year in the Department of English College of Education/Ibn Rushd for Human Sciences for administering the instrument of the study. When the assessment has submitted, it is noticed that the instructions and items are obvious but it is more convenient to exhibit an example before executing any task. The time that participants need to respond to the working memory assessment measures is 60 minutes.

To find out the reliability coefficient of the working memory assessment, Alpha-Cronbach Formula has been utilized to obtain the internal consistency among the assessment's items. The reliability coefficient of the working memory assessment is found out to be (0.906). and the reliability coefficient for each subscales; Digit Recall Task (0.718), Reading Span Task (0.723), Dot Matrix Task (0.706), Letters Matrix Task (0.811), Image-Word Task (0.820), Paired Associate Recall Task (0.864), which are all considered acceptable according to Grous (2013).

\section{Designing Language Proficiency Test}

The skills of speaking, writing, listening and reading are presumed to be assessed in a language proficiency test (ACTFL, 2012). Thus, the aim of such test is to measure various skills and components that determine the student's language level. In order to identify EFL students' language proficiency, a test has been designed based on some language proficiency 
scales and previous frameworks*. The test consists of 5 questions the first three questions comprise of 5 items with 4 options for each. The score is 2 for each item. The total score is 10 marks for each question. The fourth question comprises of 3 topics in which testers select a topic of three to talk about, and the fifth question comprises of 2 topics in which testers select a topic to write about. The total score is 20 marks (See Table 3.3).

Table (1) Components and Scores of Language Proficiency Test

\begin{tabular}{|l|l|l|}
\hline No. & Components & Scores \\
\hline Q1 & Listening Comprehension & 10 scores \\
\hline Q2 & Reading Comprehension & 10 scores \\
\hline Q3 & Language Function & 10 scores \\
\hline Q4 & Speaking & 20 scores \\
\hline Q5 & Writing & 20 scores \\
\hline Total & & 70 scores \\
\hline
\end{tabular}

The analytic rubric adopted from Brown (2001) is used for scoring the speaking skill (Question 4). The scoring criteria can be adjusted reliant on the anticipated functioning standards (Brown, 2004: 157). Hence some modifications; the components "comprehension" and "task" have been excluded since they are not appropriate for evaluating the question. Thus, it consists of four components to be rated and a rating scale (1-5)

Table (2) Components and Scores of Speaking Skill Rubric

\begin{tabular}{|l|l|l|}
\hline No. & Components & Scores \\
\hline 1 & Grammar & 5 scores \\
\hline 2 & Vocabulary & 5 scores \\
\hline 3 & Fluency & 5 scores \\
\hline 4 & Pronunciation & 5 scores \\
\hline Total & & 20 scores \\
\hline
\end{tabular}

The analytic rubric adapted from Brown (2007) is used for scoring the writing skill (Question 5) that consists of five components and has allocated 4 scores for each one.

\footnotetext{
"- Yeditepe University / Proficiency Test / Istanbul Language Academy / 2015

- Listening B2, Cambridge English First (FCE) Test / 2017
} 
Table (3) Components and Scores of Writing Skill Rubric

\begin{tabular}{||l|l|l|}
\hline No. & Components & Scores \\
\hline 1 & Content & 4 scores \\
\hline 2 & Organization & 4 scores \\
\hline 3 & Grammar & 4 scores \\
\hline 4 & Vocabulary & 4 scores \\
\hline 5 & Mechanics & 4 scores \\
\hline Total & & 20 scores \\
\hline
\end{tabular}

To ensure face validity of the language test, it has been exposed to the same jury members who agree that questions are all appropriate for measuring the language proficiency of the sample. Thus, the percentage of agreement for the suitability of the test items has been found to be $100 \%$.

However, the same pilot sample which comprises 30 students has been utilized for accomplishing the pilot purposes. No vagueness has been found in relation to the instructions and questions. The time allotted for completing the proficiency test is 40 minutes.

The reliability coefficient has been computed by Kuder-Richardson formula 20, where the reliability coefficient of the language proficiency test is found out to be (0.820) and the reliability coefficient for each subscales; Listening (0.734), Reading (0.756), Function (0.737), Speaking (0.870), Writing (0.864), which are considered acceptable according to previous studies.

The final administration of the instruments on the sample of the study which encompasses 100 of third year, EFL university students has been conducted in order to find out students' degrees of working memory capacity and levels of their Language proficiency. The instruments have been administrated on Monday, 10 of February/2020 at the Department of English Language/ College of Education, University of Baghdad and continued for two weeks

\section{RESULTS}

The aim is about "finding out the correlation between Iraqi EFL university students' working memory capacity and their language proficiency". Person correlation coefficient formula is utilized to compute the relationship between the scores of the two instruments of the research sample. Then the t-test formula has been manipulated for the significance of the correlation coefficients, and the results are shown in the table below:

Table (4) Correlation between EFL University Students' Working Memory Capacity and their Language Proficiency

\begin{tabular}{|l|l|l|l|l|}
\hline Variable1 & Variable2 & Person Correlation & t-test \\
\cline { 3 - 5 } & & & Computed & Tabulated \\
\hline $\begin{array}{l}\text { working memory } \\
\text { capacity }\end{array}$ & language proficiency & 0.451 & 5.011 & 1.960 \\
\hline
\end{tabular}

Tabulated t.test value at level of significance $(0.05)$ and degree of freedom $(98)$ is $(1.960)$. 
This table shows that Pearson correlation coefficient is found to be (0.451) at (0.05) level of significance and (98) degree of freedom. Then, the computed t-test values (5.011) is established to be bigger than the tabulated t-test values (1.960), which indicates that there is a statistically significant positive correlation between the two variables (working memory capacity and language proficiency).

\section{DISCUSSION OF RESULTS}

In the present study, a cognitive variable of student's working memory capacity has been found to be correlated with a vital learning domain which is students' EFL proficiency; as there is a positive correlation between Iraqi EFL students' working memory capacity and their language proficiency. Hence, it illustrates that whenever students' working memory capacity is medium, their language proficiency level will be medium as well.

The main finding of the current study is similar to those of Van den Noort et al (2006), Prebianca (2013) and Rezai1 \& Okhovat (2016) as they all advocate that there is a significant positive relationship between students' working memory capacity and foreign language proficiency. The general outcomes of Van den Noort et al study reinforce the hypothesis that working memory capacity interrelates with foreign language proficiency. The basic conclusions mention in Prebianca study show that working memory capacity is superficially a function of FL/L2 proficiency. The key results of Rezai1 \& Okhovat study generate that WMC plays a central a part in FL/L2 oral fluency and FL/L2 production. In contrary, this study is not compatible with Weissheimer \& Mota (2009). As they put on view that only lower span learners prove a statistically significant development in working memory capacity and it is not a reflection of increased proficiency.

\section{REFERENCES}

ACTFL American Council on Teaching of Foreign Language, (2012). ACTFL provisional proficiency guidelines. New York.

Baddeley, A. \& Hitch, G. J. (1974). Working memory. In G. Bower (Ed.), The psychology of learning and motivation (Vol. 8, pp. 47-90). New York: Academic Press.

\& Hitch, G. J. (2010) Working memory. Scholarpedia, 5(2): 3015., revision \#137215

Basta, J. (2011). The role of the communicative approach and Cooperative learning in higher education. Linguistics and Literature. 9 (2) 125-143

Bragger, J. D. (1985). Materials development for the proficiency-oriented classrrom. C. J. James (Ed.), Foreign language proficiency in the classroom and beyond (79-116). Lincolnwood: National Textbook Company.

Brown, H. D. (2001). Teaching by Principle: An Interactive Approach in Language Pedagogy, 2nd Ed. New York: Pearson Education.

(2004). Language Assessment: Principles and Classroom Practices. New York: Pearson Education, Inc.

(2007). Principles of Language Learning and Teaching. USA: Pearson Education, Inc.

Cowan, N. (2001). The magical number 4 in short-term memory: A reconsideration of mental storage capacity. Behavioral and Brain Sciences, 24, 87.

Ellis, N. C. (2001). Memory for language. In P. Robinson (ed.), Cognition and second language instruction. New York: Cambridge University Press, 33-68.

Fodor, J. D. (1998). Unambiguous triggers. Linguistic Inquiry 29, 1-36. 
Green, D. W. (1998). Mental control of the bilingual lexicosemantic system. Bilingualism: Language and Cognition, 7 , $67-81$.

Hummel, K. M. (2002). Second language acquisition and working memory. In F. Fabbro (Ed.), Advances in the neurolinguistics of bilingualism (pp. 95-117). Udine, Italy: Forum.

King, J., \& Just, M. A. (1991). Individual differences in syntactic processing: The rate of working memory. Journal of Memory and Language, 30, 580-602.

Kormos, J., \& Sáfár, A. (2008). Phonological short-term memory, working memory and foreign language performance in intensive language learning. Bilingualism: Language and Cognition, 11, 261-271.

Levelt, W. (1989). Speaking: From Intention to Articulation. Cambridge, MA: MIT Press.

Mackey, A., J. Philp, T. Egi, A. Fujii \& T. Tatsumi (2002). Individual differences in working memory, noticing of interactional feedback and L2 development. In P. Robinson (ed.), Individual differences and instructed language learning. Philadelphia, PA: John Benjamins, 181-209.

Miyake, A., \& Friedman, N. P. (1998). Individual differences in second language proficiency: Working memory as language aptitude. In A. F. Healy \& L. E. Bourne (Eds.), Foreign language learning: Psycholinguistic studies in training and retention (pp. 339-364). Hillsdale, NJ: Erlbaum.

Oberauer, K., Suß, H. M., Wilhelm, O. \& Wittman, W. W. (2003). The multiple faces of working “ memory: Storage, processing, supervision, and coordination. Intelligence 31, 167-193.

Richards, J. C., \& Schmidt, R. (2002). Longman dictionary of language teaching \& applied linguistics. (3rd edition.). Essex: Longman.

Service, E. (1992). Phonology, working memory, and foreign-language learning. Quarterly Journal of Experimental Psychology, 45A(1), 21-50.

Swanson, H. L. \& Beebe-Frankenberger M. (2004). The relationship between working memory and mathematical problem solving in children at risk and not at risk for math disabilities. J. Educ. Psychol. 96:471-491.

VanPatten B. (ed.) (2004). Processing instruction: Theory, research, commentary. Mahwah, NJ: Lawrence Erlbaum.

Wen, Z. (2012). Working Memory and Second Language Learning. International Journal of Applied Linguistics, v. 22, n. 1, p. 1-22.

White, L., Valenzuela, E., Kozlowska-MacGregor, M., \& Leung, I. Y.-K. (2004). Gender and number agreement in nonnative Spanish. Applied Psycholinguistics, 25, 105-133.

Wynn, T. \& Coolidge, F. L. (2011). The Implications of the Working Memory Model for the Evolution of Modern Cognition. Research International Journal of Evolutionary Biology Volume, 741357:10.4061/2011/741357.

Zoghbi، A. (2016). Working memory task gauge (storage-processing). Instruction booklet، Cairo: Anglo-Egyptian Library. 
اقترح عدد هائل من البحوث التي أجريت على مدى العقود الماضية أن البشر يمتلكون نظاما ذهنيا يعرف بالذاكرة العاملة. الذاكرة العاملة هي الجزء

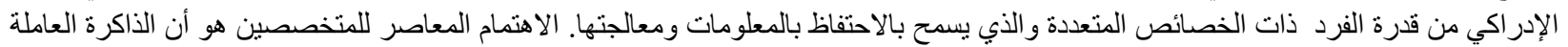

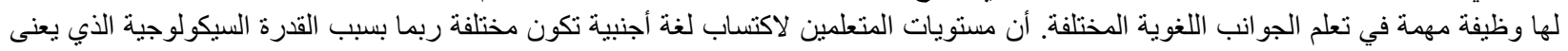

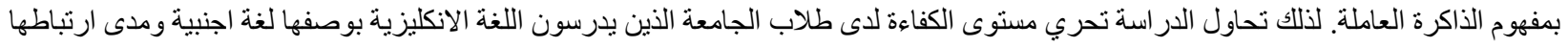

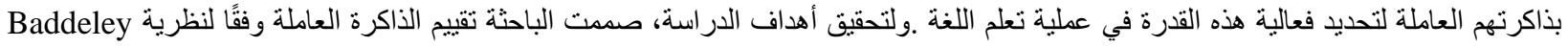

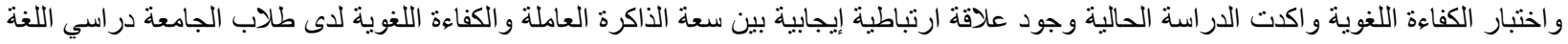

